\title{
O gênero textual comentário jornalístico radiofônico no ensino do oral: processo de elaboração de um modelo didático
}

\author{
Carla Messias*
}

\begin{abstract}
Resumo
O presente artigo tem por objetivo apresentar o processo de elaboração de um modelo didático para o gênero comentário jornalístico radiofônico, elaborado por meio da análise de exemplares desse gênero sob a base teórico-metodológica do interacionismo sociodiscursivo. Este trabalho é um recorte feito a uma pesquisa de mestrado intitulada "O modelo didático do comentário jornalístico radiofônico: uma necessária etapa para a intervenção didática" que visou à identificação das características definidoras do gênero em questão com fins didáticos, numa perspectiva de propiciar o desenvolvimento das capacidades de linguagem em alunos do ensino fundamental do $8^{\circ}$ e $9^{\circ}$ anos que faziam parte de uma proposta de projeto de rádio escolar desenvolvida, em 2008, em uma escola pública do estado de Mato Grosso.

Palavras-chave: modelo didático; comentário jornalístico; capacidades de linguagem.
\end{abstract}

\section{The textual genre radio journalistic comment in teaching oral: elaboration process of a didactic model}

\begin{abstract}
This article aims to present the process of elaboration of a didactic model for the textual genre radio journalistic comment, drew up through the analysis of copies of this genre under the interactionism sociodiscursive theoretical-methodological basis. This work is a master's degree research outline entitled "The didactic model of the radio journalistic comment: a necessary stage for the didactic intervention" that aimed the identification of the defining characteristics of this genre with didactic objectives, in order to propiciate the development of the language capacities with students from the eight and ninth years at the primary school who participated of a radio project proposal developed in 2008 at a state school from Mato Grosso State.

Key-words: didactic model; journalistic comment; language capacities.
\end{abstract}

\section{Introdução}

Este artigo tem por objetivo apresentar o processo de elaboração de um modelo didático de um gênero da oralidade, mais especificamente, o comentário jornalístico radiofônico que culminou no modelo didático propriamente dito. Como modelo didático compreende-se um objeto descritivo cuja função é nortear as práticas escolares de produção, identificando-se as dimensões constitutivas do gênero e a seleção das características que podem ser ensinadas. (DE PIETRO et al. 1996/1997, p.108).

A proposta aqui apresentada segue as pesquisas desenvolvidas por pesquisadores da Universidade de Genebra tais como Bronckart (2007), Schneuwly e Dolz (1998; 2004), bem como de pesquisadores brasileiros como Machado (2007; 2009), Machado et.al (2010; 2011), Machado e Cristóvão (2009) que, no quadro do Interacionismo Sociodiscursivo (doravante ISD), assumem a concepção de desenvolvimento do interacionismo social de Vygotsky que considera a linguagem como central para o desenvolvimento do humano.
No caso dos autores supracitados, tendo como centralidade a questão da linguagem no desenvolvimento do pensamento consciente humano, ampliam e aprofundam a concepção vygotskiana em direção à questão escolar, mais especificamente, à questão de que o ensino das práticas de linguagem permite o desenvolvimento de capacidades linguageiras nas pessoas, isto é, a capacidade de agir com a linguagem em diferentes práticas sociais, sendo isso propiciador do desenvolvimento humano. Para um ensino dessa natureza, esses autores propõem a elaboração de modelos e sequências didáticas.

Segundo esses autores, a elaboração de um modelo didático de um gênero é uma das etapas para a construção de sequências didáticas (doravante SD), isto é, sequências sistematizadas de atividades que propiciam o desenvolvimento das capacidades de linguagem em diferentes aprendizes. Para a elaboração do modelo didático (doravante $\mathrm{MD}) \mathrm{e}$, consequentemente, de $\mathrm{SD}$, devemos ter à priori a referência sobre o nível escolar dos alunos (anos ou séries), seus conhecimentos prévios em relação à um gênero específico, bem como, que

\footnotetext{
* Endereço eletrônico: carlamessias @yahoo.com.br
} 
competências de linguagem buscamos lhes oportunizar a apropriação (argumentativas, narrativas, descritivas, etc).

Para a elaboração do MD aqui proposto, analisamos cinco exemplares do gênero comentário jornalístico radifônico. Para a escolha dos cinco exemplares, analisamos, numa primeira etapa, o total de dez exemplares de comentários jornalísticos radiofônicos exibidos na emissora de Rádio Jovem Pan AM 620, de São Paulo. Para a escolha dessa rádio, levamos em consideração, basicamente, o reconhecimento público nacional quanto ao trabalho de radiojornalismo que ela exerce.

Para a apresentação de nossa proposta, organizamos o artigo em três seções. Na primeira, discutiremos o aporte teórico que embasa a elaboração do modelo didático do comentário jornalístico radiofônico. $\mathrm{Na}$ segunda seção, apresentaremos a proposta de elaboração de modelo didático de gêneros por pequisadores do interacionismo sociodiscursivo. E, em terceiro momento, mostraremos as etapas do processo de elaboração do modelo didático por nós realizado, bem como o modelo didático produto do processo.

\section{Pressupostos teóricos gerais: os gêneros como instrumento para o desenvolvimento de capacidades linguageiras}

O ser humano é um ser social e constituído por sua relação com o outro. É nesta relação com o outro e com o meio que ele desenvolve seu pensamento consciente e os conhecimentos de e para o mundo. A interação do ser humano com o meio e entre si se dá no seio das atividades sociais e/ou coletivas, "estruturas de colaboração que organizam as interações dos indivíduos com o meio" (BRONCKART, 2006, p. 138) propiciadoras do desenvolvimento humano. No centro dessas atividades sociais ou coletivas estão as atividades de linguagem ${ }^{1}$ como reguladoras da interação humana nas atividades coletivas. Essas atividades (coletivas ou de linguagem) são organizadas nas formações sociais compreendidas como "formas concretas que as organizações da atividade humana e, de modo mais geral, da vida humana, assumem, em função dos contextos físicos, econômicos e históricos". (BRONCKART, 2008; p.113).

As formações sociais, por sua vez, estabelecem normas e valores, a fim de regular e organizar as interações entre os membros de um determinado grupo social.

Essas interações são mediatizadas pela linguagem verbal em atividades linguageiras que têm no texto seus correspondentes empíricos "produzidos com os recursos de uma língua natural" (BRONCKART, 2008, p. 113). Em outras palavras, uma pessoa age linguageiramente, em uma determinada situação social, por meio de ações de linguagem, textos e gêneros de textos compreendidos como produtos linguísticos das representações de um agente sobre os contextos socioculturais e semióticos organizados em sistemas de representações coletivas, os mundos formais ${ }^{2}$.

Os mundos formais ou representados constituem-se como sistemas de coordenadas formais que organizam as representações sociais sobre uma determinada atividade. São compreendidos na ordem do psicológico por se constituírem como "configurações de conhecimentos" (BRONCKART, 1999/2007; p. 33), adquiridos e exigidos por uma pessoa para que o seu agir seja considerado válido em uma dada atividade. Assim o agir humano exibe pretensões à validade sob as quais os membros da sociedade fazem suas avaliações e/ou controles coletivos (BRONCKART, 2008).

Essas pretensões regulam e norteiam o agir linguageiro humano no quadro desses sistemas denominados de a) mundo objetivo - os conhecimentos coletivos adquiridos em relação ao mundo físico; b) mundo social - constituído pelos conhecimentos acumulados pela pessoa em relação às regras sociais, elaboradas por um grupo particular e específico e aplicadas na organização das tarefas comuns; e, c) mundo subjetivo - constituído pela soma do conhecimento coletivo acumulado pelo indivíduo engajado nos grupos sociais e de seus traços psíquicos, que constituem suas características próprias.

De acordo com Bronckart (2008), é no processo de interação verbal, durante as produções de seus textos, que uma pessoa mobiliza o conhecimento desses três mundos representados, que, consequentemente, aparecerão configurados nesses textos. Ou seja, ao serem produzidos por uma pessoa em uma determinada atividade social, os textos revelam em si o conhecimento desta pessoa vindos desses três mundos representados.

Tomando por base esses preceitos, e em uma forma de organizar as representações desses mundos formais às situações concretas de interação, alguns pesquisadores do interacionismo sociodiscursivo (genebrinos e brasileiros já citados anteriormente) apresentam uma proposta didática de trabalho com os textos e gêneros de textos em 
situação de ensino e aprendizagem que vise ao desenvolvimento de capacidades linguageiras propiciadoras do desenvolvimento do agir humano nas diversas formações e atividades sociais presentes no mundo.

$\mathrm{Na}$ realização de uma ação de linguagem (textos), o enunciador e seus interlocutores colocam em interface as representações sobre os mundos formais e o conhecimento sobre a situação de ação/produção e/ou comunicação em que se encontra, sobre os gêneros de textos, presentes nas diferentes esferas discursivas de nosso cotidiano, e sobre os recursos linguísticos de uma língua natural. É a mobilização desse conhecimento sobre esses três elementos que constituirá o que se denomina como capacidades de linguagem, isto é, um conjunto de operações que permitem a realização de uma determinada ação de linguagem. Ou, mais especificamente, como

as aptidões requeridas de um aprendiz para a produção de um gênero numa situação de interação determinada: adaptar-se às características do contexto e do referente (capacidade de ação); mobilizar modelos discursivos (capacidades discursivas); dominar as operações psicolinguísticas e as unidades linguísticas (capacidades linguísticodiscursivas) (DOLZ \& SCHNEUWLY, 2004, p. 52).

Como capacidades de ação entendemos as capacidades de mobilização dos conhecimentos referentes à situação de produção, ou seja, a mobilização, pelo produtor, de suas representações do meio físico e social em que a produção se desenvolve (enunciador, destinatário, objetivo, lugar social) e a adoção ao gênero. Como capacidades discursivas compreendemos a mobilização de conhecimentos sobre a organização textual, como por exemplo, a identificação dos tipos de discurso e sua articulação, a identificação do plano global do texto e das sequências. $\mathrm{E}$ as capacidades linguístico-discursivas, de acordo com Machado (2007), envolveriam a mobilização das operações de textualização, ou seja, as operações de conexão, coesão (nominal e verbal) e modalização, as construções de enunciados e de seleção de itens lexicais.

A proposta de elaboração de modelos didáticos (MD) e sequências didáticas (SD) centrase na questão de ensino das práticas linguageiras situadas (os textos e os gêneros de textos), possibilitando o desenvolvimento dessas capacidades linguageiras nas pessoas, isto é, da capacidade de agir com a linguagem em diferentes práticas sociais. Os MD e SD são, portanto, dispositivos didáticos que colocam em cena as diferentes dimensões de um texto, a fim de desenvolver as diferentes capacidades e competências linguageiras dos aprendizes. Nesse caso, os textos e os gêneros textuais são o objeto de ensino geral a ser objetivado na elaboração dos modelos e sequências didáticas, a fim de propiciar o desenvolvimento de capacidades múltiplas.

É ao lado dessa perspectiva didática que Schneuwly (2004) e Dolz e Schneuwly (2004) propõem a noção de gênero como instrumento e megainstrumento no processo de ensino aprendizagem para o desenvolvimento do pensamento consciente humano.

O uso dessas metáforas "instrumentos e megainstrumentos", associadas aos gêneros de textos, podem ser explicados, segundo Schneuwly (2004), da seguinte forma: são ferramentas ou instrumentos enquanto objetos específicos elaborados socialmente e sobre ou com os quais uma pessoa age a fim de realizar sua ação. No caso dos gêneros, esses funcionam como instrumentos, pois são construtos sociais linguageiros, cujos modelos podem ser apropriados e usados pelas pessoas em uma dada ação de linguagem. $\mathrm{O}$ gênero seria também um megainstrumento por comportar uma diversidade de configurações "estabilizadas de vários subsistemas semióticos (sobretudo linguísticos, mas também paralinguísticos)" (Schneuwly, 2004, p. 28), como também por permitir a atuação da pessoa sobre o meio, possibilitando o desenvolvimento das várias capacidades de linguagem.

Ao considerá-lo como instrumento ou megainstrumento, os autores do ISD, fazem-no sob três ângulos, apontados por nós em um de nossos artigos (Messias, no prelo). O primeiro, no sentido de que o gênero dotado das características (unidade de conteúdo temático, composição e estilo) pode ser "adaptado a um destinatário preciso, a um conteúdo preciso, a uma finalidade dada numa determinada situação". Esse funcionamento pode ser objeto de análise e ensino (Schneuwly, 2004, p.27).

$O$ segundo, no sentido de que os gêneros prefiguram as ações de linguagem possíveis, mesmo que parcialmente, da seguinte forma: os gêneros já existentes ou disponíveis no intertexto servem como modelos a serem apropriados por um sujeito quando 
realiza sua ação de linguagem, tendo em vista a situação de linguagem que o envolve. Ressaltam os autores do ISD que essa apropriação ocorre por meio de operações psicolinguísticas.

E, terceiro, no sentido de que a estrutura organizacional do gênero (tratamento do conteúdo, tratamento comunicativo e tratamento linguístico) pode servir como guia para o uso dos diferentes níveis de operações necessárias para a produção de um texto pertencente a um gênero.

Dessa premissa, surge a proposta da elaboração de modelos didáticos ${ }^{3}$ (MD) para o trabalho com os gêneros. De fato, não se trata do ensino do gênero pelo gênero, mas de "aprender a dominar o gênero, primeiramente, para melhor conhecê-lo ou apreciá-lo, para melhor saber compreendê-lo, para melhor produzi-lo na escola ou fora dela", e também de "desenvolver capacidades que ultrapassam o gênero e que são transferíveis para outros próximos ou distantes". Os gêneros seriam, dessa forma, "instrumentos" ou "megainstrumentos", que, quando apropriados por um sujeito, tornar-se-iam mediadores do conhecimento, usados nas interações verbais, nas mais variadas situações comunicativas tanto formais quanto informais. (SCHNEUWLY e DOLZ, 2004, p. 80).

Essa proposta vem de uma preocupação primeira dos pesquisadores da Unidade de Didática de Línguas voltada ao ensino de francês como Língua Materna que se refere ao "problema das condições de adaptação dos modelos teóricos e dos resultados das pesquisas empíricas à realidade das salas de aula e do trabalho do professor" no que diz respeito ao ensino de língua materna e a adaptação da concepção de gêneros à realidade de sala de aula (BRONCKART, 2006, p.13). Era uma preocupação, portanto, de transposição didática ${ }^{4}$, ou seja, uma preocupação sobre como os estudos sobre gêneros do discurso/textos estavam sendo abordados nos planos curriculares e como eles efetivamente chegavam à sala de aula.

A seguir, explicaremos as propostas dos pesquisadores do interacionismo sociodiscursivo para a elaboração de MD.

\section{Uma proposta para a elaboração de modelo didático de gêneros.}

Na elaboração de um modelo didático, de acordo com Schneuwly e Dolz (2004), alguns fatores devem ser considerados por parte dos pesquisadores e professores etc:
1. a compreensão de que o gênero trabalhado na escola é sempre "uma variação do gênero de referência, construída numa dinâmica de ensinoaprendizagem, para funcionar numa instituição cujo objetivo primeiro é o do ensino". (Schneuwly e Dolz 2004: 81)

2. a compreensão de que há a existência de três princípios a serem observados: o princípio de legitimidade, isto é, ter referência sobre os saberes teóricos a respeito do gênero, ou seja, sob qual aporte teórico o gênero está sendo abordado e/ou o que os profissionais especialistas que lidam com o gênero abordado dizem; o princípio da pertinência que incide sobre as finalidades de se trabalhar com esse gênero, as capacidades dos alunos, os objetivos que se quer alcançar e o processo de ensino aprendizagem; e, o princípio de solidarizarão, ou seja, tornar claro a quais saberes destina-se o ensino, tendo em vista os objetivos pretendidos (SCHNEUWLY e DOLZ 2004, p. 82).

Além desses dois fatores, Dolz, Schneuwly e Haller (2004, p.108) apresentam quatro dimensões também a serem consideradas:

1. a psicológica, motivação e interesses dos alunos para a produção dos textos pertencentes ao gênero a ser trabalhado;

2. a cognitiva, o conhecimento dos alunos sobre o gênero e os temas discutidos;

3. a social, a relação do tema e do gênero com o contexto real presente no ambiente interior e exterior da escola;

4. a didática, a escolha de um tema que não seja extremamente cotidiano

De acordo com essas considerações, os autores supracitados sugerem os seguintes passos a serem seguidos:

- $\quad$ Fazer o levantamento das teorias existentes sobre as ciências do discurso que discutem as noções de gênero.

- Fazer levantamento do conhecimento que já existe sobre o gênero específico: tanto no nível dos saberes científicos quanto no nível dos experts, ou seja, conhecimento constituído pelos profissionais especialistas que utilizam e produzem textos referentes a esses gêneros.

- Fazer levantamento das características desse gênero: a situação de comunicação ou contexto de produção, o conteúdo, a estrutura comunicativa e composicional e as configurações específicas das unidades linguísticas.

Quanto ao levantamento das características específicas do gênero, diferentes teórias podem ser adotadas, entretanto, para os pesquisadores do ISD é 
o modelo de produção e análise de textos no quadro desta teoria que pode proporcionar, de fato, o desenvolvimento sistemático das diferentes capacidades linguageiras já descritas neste artigo. Vale ressaltar que, em alguns casos, esses autores trazem conhecimentos linguísticos e discursivos de outras teorias.

Machado e Cristóvão (2009) apresentam, dessa maneira, uma proposta de levantamento da característica do gênero, com os aspectos delineados no modelo de produção e análise de texto proposto por Bronckart (1999/2007).

Dessa descrição, o primeiro elemento refere-se aos parâmetros constitutivos da situação de produção (emissor, receptor e o papel social assumido por eles, local físico e instituição social, momento de produção, suporte, objetivo e valor social). O segundo e o terceiro elementos aludem, respectivamente, à elaboração do conteúdo típico do gênero e à forma de mobilizá-los (quais são os conteúdos mais específicos a esse gênero, quais as operações de linguagem necessárias para construílo). $\mathrm{O}$ quarto elemento está relacionado à sua construção composicional (o plano global mais comum). E, o último, ao seu estilo particular que engloba as configurações específicas de unidades de linguagem (traços de posição enunciativa do enunciador), os tipos de discursos, as sequências textuais, as características do mecanismo de textualização (coesão nominal e verbal, conexão), características lexicais.

\section{O processo de elaboração do modelo didático do comentário jornalístico radiofônico.}

Nesta subseção, apontaremos as cinco etapas e os passos realizados na elaboração do modelo didático do comentário jornalístico radiofônico.

\subsection{Etapas antecedentes à análise dos textos pertencentes ao gênero comentário jornalístico radiofônico.}

São quatro as etapas que antecederam as análises. São elas:

1. A escolha do gênero a ser trabalhado. $\mathrm{Na}$ realização desta etapa, foram levadas em consideração as quatro dimensões propostas por Dolz, Schneuwly e Haller (2004). Em um contexto de um projeto de rádio escolar, escolhemos um gênero para ser trabalhado com alunos de $8^{\circ}$ e $9^{\circ}$ anos, participantes desse projeto, a fim de serem produzidos textos para serem veiculados no momento dos intervalos das aulas nos programas radiofônicos organizados pelos alunos participantes do projeto. A opção pelo gênero comentário jornalístico radiofônico levou em consideração três fatores. O primeiro, por ele ser um gênero argumentativo de caráter opinativo que exige do seu produtor um conhecimento profundo e especializado sobre o tema abordado em seu texto, a fim de expor um ponto de vista crítico, com uma argumentação consistente. $\mathrm{O}$ segundo, não dissociado do primeiro, por ser um gênero que exige do produtor, além do conhecimento especializado, a atualização sobre a sua realidade social. O terceiro, por acreditarmos que o ensino desse gênero pode contribuir para o desenvolvimento de diferentes capacidades de linguagem ainda não desenvolvidas pelos alunos, sendo essas relacionadas ao domínio da oralidade e escrita.

2. O levantamento do conhecimento teórico sobre gêneros de textos e discursivos (no geral) $e$ sobre os gêneros do radiojornalismo. Nesta fase buscou-se compreender o que dizem alguns teóricos sobre as teorias de gênero e texto, mais especificamente Bakthin (2003), Adam (1997; 2008), Bronckart (1999/2007; 2006;2008), Coutinho (2003), Marcuschi (2008) e Koch (2003), bem como o que dizem os profissionaispesquisadores da área do radiojornalismo, mais especificamente Barbosa Filho (2003), Babeiro e Lima (2003), Melo (1985) e Beltrão (1980). Partindo dessas leituras, no que diz respeito ao conhecimento teórico geral sobre os gêneros textuais e/ou discursivos, optamos pelos aportes teóricos do interacionismo sociodiscursivo, mais especificamente Bronckart e Coutinho, como base central, visto que esta teoria, com fontes em Baktin/Voloshínov em sua obra "Marxismo e filosofia da linguagem", propõe um modelo de produção e análise que incide sobre as diferentes dimensões do texto : contextuais, discursivas e linguísticas, sendo esse modelo reconhecido como folhado textual, pois todas as dimensões aparecem superpostas e dependentes umas das outras. Associada a essa teoria de base, também nos apoiamos nos estudos de Marcuschi (2008) sobre as noções de suporte e gênero.

No que se refere aos estudos da área do radiojornalismo, os autores supracitados apresentaram, de forma geral, alguns aspectos da linguagem radiofônica que precisam ser ressaltados em produções do radiojornalismo: a voz e a entonação do locutor a fim de atingir seus 
destinatários/público, o uso de vinhetas, a repetição de termos centrais para a compreensão do texto produzido pelo locutor a fim de permitir que um ouvinte, a qualquer instante, possa acompanhar o tema discutido.

Esses levantamentos bibliográficos e as escolhas teóricas guiaram a elaboração do modelo didático, pois foi sob essas perspectivas que foram realizadas as análises das características do comentário jornalístico radiofônico.

3. Levantamento do conhecimento constituído pelos profissionais da área. Nesta etapa, foram realizadas duas entrevistas com dois radialistas pertencentes a duas emissoras de rádio da cidade de Barra do Garças-MT, um radialista com catorze anos de experiência profissional e outro com seis anos. Por meio dessas entrevistas foi possível obter informações importantes sobre a atividade radiofônica e do jornalismo radiofônico propriamente dito. Entre essas informações destacamos as que dizem respeito à produção textual.

a. Em relação ao conteúdo temático de suas produções, ambos frizaram a importância de estarem informados sobre os acontecimentos e fatos históricos locais e do mundo por meio de leituras de textos escritos que falem sobre o assunto a ser discutido. Esses textos podem ser de jornais impressos, livros variados etc, bem como, se possível, assistir a programas televisivos que abordem a mesma temática (jornais televisivos para o conteúdo do radiojornalismo e outros programas para os demais).

b. Em relação aos textos escritos que acompanham as produções orais. Esses textos devem servir como um respaldo ao radialista, não para ser lido tal qual escrito, mas adaptado para a oralidade.

c. Em relação aos destinatários/ouvintes, de acordo com os entrevistados, os apresentadores dos programas, os reporteres e/ou jornalistas devem ter em mente o público alvo de seu programa e falar diretamente a esse público: "por exemplo, se eu quero atingir as donas de casas mais velhinhas que estão em suas casas no final da tarde eu vou dizer de forma geral: e aí dona Maria e aquele cafezinho..." $(\text { radialista } B)^{5}$.

d. Em relação ao comentário jornalístico, para ambos, este constitui como um texto "mais elaborado" (radialista A), que exige um conhecimento político geral e da atualidade, bem como conhecer a argumentação a fim de convencer o ouvinte a respeito de um ponto de vista: "esse é um texto mais elaborado, eu nao costumo fazer porque meu programa é outro, faço outros tipos de acordo com o meu programa, mas os comentários... para fazer precisa ter uma boa argumentação e brincar muito com as palavras e as vezes ser um pouco ironico também..." (radialista $A^{6}$ )

4. Escolha dos exemplares a serem analisados para a elaboração do modelo didático. Dividimos esta etapa, a título de apresentação neste artigo em dois momentos. No primeiro momento foram coletados em áudio e, em seguida, transcritos dez exemplares de comentários jornalísticos postados em um site da rádio CBN/SP. Após uma primeira análise linguística-textual, constatamos que as marcas da oralidade (formal e informal) não estavam presentes. Como são textos que ficam expostos no site da rádio, em suas produções esse aspecto é levado em consideração pelos produtores que os fazem para serem consultados posteriormente. Essa constatação nos permitiu afirmar que ao se tratar de escolhas para a elaboração de um modelo didático com fins de ensino aprendizagem para o desenvolvimento de capacidades linguageiras referentes a um gênero $X$ (da oralidade ou escrita), que tem como atividade e suporte o radiojornalismo, a coleta precisa ser realizada em programas radiofônicos em tempo real (em suportes materias como o rádio ou $\mathrm{o}$ computador ou iphone, etc).

O segundo momento é decorrente da constatação a que chegamos no primeiro momento. Nesta fase, partimos para a escolha de uma emissora de rádio e dos programas a serem observados para a coleta dos comentários. A emissora escolhida foi a Rádio Jovem Pan AM 620 de São Paulo pelo reconhecimento público nacional quanto ao trabalho de radiojornalismo que ela exerce. Foram três os programas selecionados: Jornal da Manhã, Jornal de Serviços e Jornal da Noite, por serem programas já, por nós, conhecidos. Desses programas foram realizadas as gravações de seis segmentos completos dos quais selecionamos e transcrevemos inicialmente o que poderia ser considerado como comentário jornalístico radifônico, o total de dez exemplares, e após uma primeira análise desses textos, constatamos que apenas cinco seriam realmente comentário jornalístico radiofônico.

3.2 Etapa correspondente à análise dos cinco textos exemplares do comentário jornalístico radiofônico. 
Nesta etapa foi realizada a análise dos textos escolhidos, tomando como parâmetros para a caracterização desse gênero o modelo de produção e análise do interacionismo sociodiscursivo (Bronckart, 1999/2007), Machado e Bronckart (2009) nos seguinte aspectos: o levantamento das condições de produção dos textos e a análise da arquitetura textual.

Os elementos das condições de produção de textos observados neste modelo de produção e análise são: a) a atividade social e linguageira em que o gênero é produzido ou esfera de circulação; b) o suporte como meio/veículo/lócus de circulação; c) contexto linguageiro imediato que comporta os textos que circulam em um mesmo suporte, cuja temática se relaciona com o texto analisado e que trazem informações que possibilitam sua interpretação; d) $\mathrm{O}$ contexto sociohistórico mais amplo compreendido como período histórico em que o texto é produzido tendo em observância as relações e os acontecimentos sociais, políticos e econômicos da época, relacionado ao conteúdo temático do texto em questão; e, e) a situação de produção ou situação de comunicação ou situação de ação de linguagem que corresponde aos parametros do enunciador (produtor físico e social do texto), destinatário (pessoa a quem se destina o texto produzido representações sociais que o enunciador tem do destinatário de suas produções), lugar social (papel da instituição.) e o objetivo (efeitos que o enunciador quer causar no destinatário).

A arquitetura textual engloba os aspectos dos três níveis do texto. O nível da infraestrutura, também compreendido como organizacional ou discursivo, que diz respeito ao plano global ou a forma como o conteúdo temático é organizado pelo enunciador na produção de seu texto, aos tipos de discurso, ou seja, as formas linguísticas que traduzem ou semiotizam os mundos discursivos, sendo eles discurso teórico, discurso interativo, narração e relato interativo e aos tipos de sequências que são os modos de planificação do conteúdo temático, isto é, as sequências argumentativas, explicativas, narrativas, injuntivas, dialogal e descritivas.

O nível dos mecanismos de textualização que engloba os mecanismos de conexão, isto é, os organizadores textuais lógico-argumentativos, tais como as conjunções portanto, mas ou temporal tais como advérbios ou adjuntos adverbiais ao entardecer, na manhã seguinte; os mecanismos de coesão nominal como, por exemplo, o uso de anáforas nominais ou pronominais; e os mecanismos de coesão verbal como o emprego dos tempos verbais de acordo com os tipos de discurso, indicando as atitudes de locução.

E, também o nível dos mecanismos enunciativos, ou seja, as marcas que apresentam a responsabilidade enunciativa em relação a conteúdo exposto. São elas: as vozes que podem ser compreendidas como entidades que assumem a responsabilidade do que é enunciado no texto, por exemplo, a voz social, do autor ou de personagens no caso do uso do discurso direto e indireto; as modalizações reconhecidas como as unidades linguísticas responsáveis por expressar as avaliações, julgamentos e comentários da instância enunciativa sobre o conteúdo exposto no texto. Pode ser deôntica, lógica, apreciativa e pragmática ou subjetiva.

Tal como esse modelo de análise é sugerido e explicado por seus autores, como não sendo os níveis estanques e/ou isolados uns dos outros, e nem os elementos das condições de produção observados afastados da arquitetura textual, mas sim que se encontram em um movimento dialógico, nesta etapa, embora a título de nossa apresentação, neste artigo, apareça uma análise em ordem linear, o processo de análise é considerado, por nós, como um ir-e-vir constante, visto que a identificação dos elementos constitutivos das condições de produção do texto só foi possível por uma análise linguística mais fina, da mesma forma como a compreensão do conjunto dos elementos linguísticos expressos no texto só é possibilitada pelo reconhecimento dos elementos constitutivos das condições de produção do texto.

\subsubsection{As características dos comentários jornalísticos radiofônicos analisados.}

Em relação ao parâmetro das condições de produção do comentário jornalístico, no momento de fazer o levantamento sobre os conhecimentos a respeito dos elementos que o constitui, nos reportamos às informações gerais obtidas nas etapas 2 e 3, associadas aos níveis linguísticos e discursivos.

Sobre os parâmetros atividade e suporte, o levantamento bibliográfico e o que diz os profissionais da área sobre seu próprio trabalho, possibilitou a percepção dos diferentes recursos utilizados pelos produtores dos comentários votlados à linguagem radiofônica percebidas no nível da análise linguística e paralinguísticas (as 
pausas e entonações por exemplo).

No que diz respeito ao parâmetro contexto sócio-histórico mais amplo, fizemos um levantamento dos acontecimentos históricos e sociais da atualidade de acordo com o tema expresso em cada comentário, a fim de compreendermos o conteúdo temático de cada texto, já que os produtores dos textos reportavam-se a esses acontecimentos como uma ancoragem para a sua produção propriamente ditos. Como por exemplo, um dos comentários, comentário $A^{7}$, reporta-se a um tema debatido na época (fevereiro de 2008) em relação à uma lei de proibição de se fumar em interiores de locais públicos (comentário político e social); outro, comentário $B^{8}$, em relação a morte de Fidel Castro e seu regime político implantado em Cuba (comentário político); outro ainda, comentário $D^{9}$, sobre os problemas dos bancos suíços (comentário econômico e político). Desta dimensão da análise, pudemos constatar duas questões importantes: o enunciador dos comentários precisa estar atento aos conhecimentos históricos e da atualidade, a fim de ancorarem suas produções, realizarem o jogo argumentativo e a exposição de seu ponto de vista, bem como os destinatários precisam estar atualizados quanto aos fatos para fazerem sua própria interpretação da situação discutida pelo enunciador.

Em relação ao contexto linguageiro imediato, o fato de havermos gravado segmentos inteiros de um mesmo programa, possibilitou notarmos a ancoragem do conteúdo temático a outras materias exibidas no mesmo programa, sendo essas matérias constituindo-se como informações adicionais aos comentários, bem como a ancoragem em textos de outros meios de comunicação, mais especificamente o jornal impresso "Estado de São Paulo" (Comentário B). Essa constatação nos permite inferir que uma das representações que o enunciador tem de seus destinatários é a de que eles acompanham os acontecimentos políticos, economicos e sociais gerais, bem como o programa onde é veiculado o seu comentário.

O último parâmetro deste nível de análise é a situação de produção, também compreendida como situação de ação de linguagem, situação de comunicação ou enunciação. A situação em que se encontram os produtores dos comentários jornalísticos, constatamos, em nossa pesquisa, que ela é prioritariamente uma situação de argumentação monologal, podendo, em alguns casos ser gerada por uma questão imposta por interlocutor como foi o caso do comentário $\mathrm{C}^{10}$. Nessa situação, o produtor tem a responsabilidade de comentar ou expor seu ponto de vista em relação a um acontecimento atual de ordem política, social, econômica nacional ou internacional, discutindo questões sobre as quais não se tem consenso. Por exemplo, no comentário $\mathrm{B}$, o produtor comenta a respeito da renúncia de Fidel Castro e expõe sua tese de que ele representou uma visão de revolução, e como justificativa e apoio para essa tese traz fatos históricos e vivências pessoais.

Sobre a situação de produção, fizemos, primeiramente, o levantamento da possível representação de si mesmos que os produtores/enunciadores devem ter mobilizado para a produção. Para isso, tomamos por base informações referentes à atividade. Observamos que eles são profissionais da área do jornalismo, conhecidos pelo estatuto de comentaristas, fazem parte do quadro de funcionários da emissora de Rádio Jovem Pan AM 620 e figuram entre as pessoas responsáveis por expor a opinião sobre notícias exibidas no Jornal da Manhã e Jornal de Serviços. Como representante de uma instituição jornalística, com o estatuto de comentarista, é lhes atribuída autoridade para se manifestar sobre determinado fato (notícia, acontecimento) exibido ou não no programa do dia. No quadro I, a seguir, resumimos as possíveis representações sobre o papel social que os jornalistas mobilizam para a produção.

\begin{tabular}{|c|c|c|}
\hline Comentários & Emissor & Enunciador (papel /função social) \\
\hline A & Carlos Chagas & $\begin{array}{l}\text { Jornalista, comentarista da seção 'A Palavra da Corte' e } \\
\text { correspondente da sucursal da Jovem Pan AM em Brasília. }\end{array}$ \\
\hline $\mathrm{B}$ & Joseval Peixoto & $\begin{array}{l}\text { Jornalista, comentarista, âncora }{ }^{11} \text { do programa Jornal da } \\
\text { Manhã. }\end{array}$ \\
\hline $\mathrm{C}$ & $\begin{array}{l}\text { José Nêumanne } \\
\text { Pinto }\end{array}$ & Jornalista e comentarista da seção 'Direto ao Assunto'. \\
\hline $\mathrm{D}$ & Reali Júnior & Jornalista, comentarista e correspondente internacional. \\
\hline $\mathrm{E}$ & Joseval Peixoto & $\begin{array}{l}\text { Jornalista, comentarista e âncora do programa Jornal da } \\
\text { Manhã. }\end{array}$ \\
\hline
\end{tabular}

Quadro I: Indicação do produtor no contexto de produção físico e sociossubjetivo ${ }^{12}$ 
A função social assumida pelos enunciadores no exercício de sua atividade profissional contribui para as "escolhas" do conteúdo temático e organização da estrutura textual, por exemplo, Carlos Chagas discute o projeto de lei em discussão no congresso em Brasília, Reali Júnior fala sobre o problema bancário europeu na época. Compreender o papel assumido pelos produtores dos comentários é importante para a construção de um modelo didático, pois ao serem transpostos para as situações de ensino esses saberes sobre o papel assumido pelo enunciador na situação de produção contribuirá para que os alunos construam seus papéis na situação em que se encontram.

Além da representação de si mesmo e do papel que ele assume, o enunciador/produtor também tem as representação sobre o destinatário ou público alvo, o papel social da emissora que ele está representando, o objetivo que busca alcançar. Sendo que essas representação influenciam na forma da planificação do conteúdo temático e sua organização sequencial.

No que se refere à representação sobre o destinatário, levamos em consideração as informações coletadas na etapa 3 por meio das entrevistas realizadas com os profissionais da área, bem como outros aspectos dos níveis de análise adotados, como o suporte (neste caso a emissora Jovem Pan), o contexto linguageiro imediato, o conteúdo temático. Desse modo, o destinatário ou neste caso, o público-alvo, é um ouvinte que acompanha a programação do Jornal da Manhã, visto que alguns dos comentários analisados se ancoraram em outras matérias exibidas no programa, um ouvinte que está atento as notícias da atualidade e podem ter opiniões diferentes do produtor em relação ao tema comentado, por ser essa uma situação de argumentação. Tanto para as situações do dia a dia, quanto para o processo de didatização, compreender a quem se destina em potencial as produções dos comentários contribui para uma interpretação dos textos expostos no cotidiano, como também para que os aprendizes em situação de ensino aprendizagem possam ter representações dos seus possíveis destinatários.

Quanto a esse aspecto, vale ressaltar que um texto ao ser produzido e veiculado toma alcances inimagináveis, entretanto, no ato da produção, há um destinatário/um interlocutor ou um público imaginado pelo enunciador e será a esse destinatário que ele irá se direcionar, embora saiba que poderão existir outros destinatários em quem ele não havia pensado.

A análise que realizamos no nível da arquitetura textual está intrinsecamente ligada a observação dos aspectos das condições de produção dos textos. Em relação ao nível da infraestrutura, na planificação do conteúdo temático retomamos os aspectos do contexto sócio-histórico mai amplo em relação ao tema abordado por cada comentarista, e identificamos que neste primeiro nível que os planos de textos ou plano global são constituídos de uma organização sequencial argumentativa ao mesmo tempo que apresentam formas diferentes de apresentar as fases da argumentação, o que é atribuído às representações que o produtor tem sobre sua situação de produção e o conhecimento deste sobre os outros aspectos das condições de produção. 
Plano de texto/plano global do comentário A

Plano Global

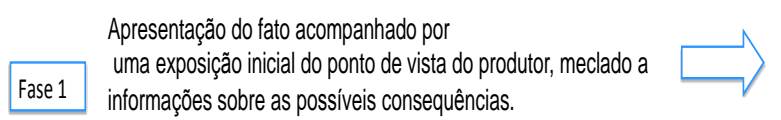

2 tese a ser defendida pelo produtor, juntamente com a

tese a ser defendida pelo produtor

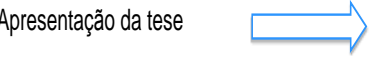

Apresentação de uma solução para o problema indicado na tese com o uso de frases impertativas.

Conclusão em que o produtor confirma a tese defendida, apresentando uma possivel restrição à solução dada e introduzindo um fato novo (de forma - irônica) que se refere a uma problemática vivida no cenário nacional brasileiro na época

Ainda no nível da infraestrutura, fizemos um levantamento sobre os tipos de discursos e constatamos que o tipo predominante é o discurso interativo, o que associamos à função desse gênero na atividade jornalística radiofônica, como também ao suporte. Para isso identificamos os tempos e as pessoas verbais, bem como o uso de advérbios e locuções adverbias temporais e espaciais que indicam o nível de implicação do enunciador e dos destinatários nos atos de locução. Por exemplo,

[...] Mas Fidel representou uma visão de revolução da década [de ...] do início da década de sessenta // Eu leio na sua carta jornal/ todos os jornais publicam hoje a carta de renúncia com mensagem do comandante $[N \ldots .$.$] /a mensagem final //$ Observa que a carta de Fidel é dirigida a um jornalista $[\ldots] / /^{13}$ (Comentário B)

Aqui / Jovem Pan Paris / tempo nublado / chuvas esparsas / temperatura em elevação // Neste momento às margens do Sena junto à Maison de la radio os termômetros marcam oito graus / a máxima será de onze $/ /{ }^{14}$ (Comentário D).

Em relação ao nível dos mecanismos de textualização, no primeiro plano, notamos uma característica mais específica da oralidade, o predomínio da justaposição dos períodos, como o uso implícito de organizadores textuais. Identificamos também a presença de organizadores

\section{Comentário A}

lecidiu o governo encaminhar ao congresso o projeto de lei proibindo o fumo em qualquer local fechado do território nacional // Vai ser difícil fiscalizar a casa de cada pessoa / mas em locais públicos acabou a faculdade de fumar // Os restaurantes e bares não poderão mais manter sequer aqueles chiqueirinhos / mesas localizadas ao lado da cozinha / ao lado dos banheiros onde ainda se podia fumar // Áreas especiais, nunca mais! // A pergunta que se faz é : "Da noite para o dia o palácio do planalto vai ser considerado local aberto?"// Porque 0 presidente Lula continua fumando // Adora cigarrilhas e obviamente não utiliza em solenidades formais / mas não evita sequer em longas entrevistas com a imprensa / quanto mais no interior do seu fechadíssimo gabinete e até no aerolula // Não constitui crime nenhum a pessoa fumar / muito menos 0 Presidente da República porque o cigarro entre os mil males que causa / possui pelo menos a virtude de aliviar tensões // Jamais se condenará o Lula por fumar / mas ele poderá responder no futuro por haver endossado a perseguição desmedida dos fumantes // Os fumantes estão sendo transformados em réprobos cidadãos de segunda classe // Nada mais natural do que proibir o fumo nos aviões/ ônibus/ trens/mesmo em certas repartições públicas e estabelecimento de uso continuado da população // Agora proibir totalmente como se o fumante fosse o grande culpado pelo fumo não // Se querem acabar com o cigarro / então tomem coragem e fechem as fábricas // Interditem 0 comercio // Só que o problema é que em matéria de impostos / as fábricas e 0 comércio ocupam o primeiro lugar na geração de renda para os cofres públicos // Sem os pulmões dos viciados em cigarro talvez até fosse reduzido drasticamente o número dos cartões de crédito coorporativos //

textuais explícitos, sendo alguns deles próximos à oralidade: alguns deles, com a função de organizador textual também funcionam como índices de marcas conversacionais (bem, agora).

$/ /[\ldots]$ Bem o Lula tem razão quando diz que 2010 está longe / tem dois anos e nós sabemos que dois anos em política são uma eternidade // Agora o raciocínio que eu quero trazer aqui para você parece até meio insistente né?[...] // (Comentário C).

Notamos, no segundo plano, uma forte presença de anáforas nominais por substituição e por repetição, o que compreendemos como sendo uma característica peculiar da linguagem radiofônica, em que os textos são transmitidos por via oral, havendo uma necessidade do uso desses recursos a fim de que o ouvinte possa compreender o conteúdo discutido a qualquer momento em que começar a acompanhar a emissão.

[...]Porque o presidente Lula continua fumando// Adora cigarrilhas e obviamente não utiliza em solenidades formais / mas não evita sequer em longas entrevistas com a imprensa / quanto mais no interior do seu fechadíssimo gabinete e até no aerolula // Não constitui crime nenhum a pessoa fumar / muito menos o Presidente da República porque o cigarro entre os mil males que causa / possui pelo menos a virtude de 
aliviar tensões // Jamais se condenará o Lula por fumar / mas ele poderá responder no futuro por haver endossado a perseguição desmedida dos fumantes [...].(Comentário A).

Em relação ao nível dos mecanismos enunciativos, notamos em um primeiro plano, uso do mecanismo de inserção de vozes pelo produtor, sobretudo para reforçar, por meio de vozes de outros, a tese por ele defendida. Tal como em "[...] Bem, eu já comentei aqui pra você / a pesquisa da CNT Sensus no que se refere à popularidade de Lula [...]" (Comentário C). Em um segundo planos, analisamos as modalizações utilizadas pelos comentaristas, o que nos mostrou a predominância da modalização lógica ou epistêmica e que seus usos contribuíram para o movimento argumentativo dos comentários, ao revelarem julgamentos e avaliações dos produtores sobre os enunciados produzidos, associando-os aos julgamentos e avaliações dos destinatários.

Os restaurantes e bares não poderão mais manter sequer aqueles chiqueirinhos / mesas localizadas ao lado da cozinha / ao lado dos banheiros onde ainda se podia fumar. (Comentário $\quad$ A). Modalização lógica/epistêmica.

Porque o presidente Lula continua fumando//Adora cigarrilhas e obviamente não utiliza em solenidades formais / mas não evita sequer em longas entrevistas com a imprensa / quanto mais no interior do seu fechadíssimo gabinete e até no aerolula. (Comentário $\quad$ A). Modalização Lógica/Epistêmica.

Terminada a análise, iniciamos a elaboração do modelo didático propriamente dito.

\subsection{O modelo didático elaborado}

Tomando por base a análise realizada, o contexto de ensino do comentário jornalístico radiofônico específico de nossa análise e o nível escolar dos alunos ( $8^{\circ}$ e $9^{\circ}$ anos), produzimos um modelo didático em que consideramos todas as características encontradas como possíveis de compor esse modelo didático. Optamos por um modelo que inicialmente trouxesse uma explicação sobre que gênero é esse, em que atividades e suportes podemos encontrá-lo, em qual situação ele é produzido e quais são os elementos constitutivos dessa produção.

Para essa primeira explicação, trouxemos o resultado da análise dos aspectos das condições de produção de textos, definindo esse gênero como um gênero que se realiza na atividade jornalística radiofônica, numa situação de argumentação específica em que o produtor (comentarista) comenta e analisa, criticamente, o agir humano em outras atividades sociais (política, econômica etc), assumindo um ponto de vista, defendendo uma tese sobre uma questão considerada controversa, com o objetivo de convencer, modificar ou formar a opinião de seu destinatário.

Em seguida, organizamos um modelo didático apoiando, em todos os seus níveis, nos elementos constitutivos das condições de produção.

1. A situação de produção ou de ação de linguagem, conforme já expresso, é uma situação de argumentação monologada em que o enunciador é um profissional da área do jornalismo, reconhecido socialmente na função de comentarista, a quem é atribuído um papel de autoridade para analisar, avaliar, julgar, direcionar a ação do outro e sugerir soluções para o que é discutido. No caso de um projeto de rádio escolar, os alunos precisam compreender o papel assumido pelo produtor da atividade de referência e, em seguida, ter a compreensão do seu papel e da própria função da rádio escolar. Na situação de ação de linguagem da atividade de referência, os destinatários são pessoas que se atualizam sobre os acontecimentos e debates políticos(ou outros) da atualidade, acompanham diariamente o programa como ouvintes assíduos estão a par da discussão levantada pelo comentarista. No projeto de rádio escolar, os produtores dos comentários precisam ter claro quais serão seus destinatários: toda a comunidade escolar, apenas os alunos, alunos de uma classe específica, ouvintes de uma rádio local, etc.

2. No nível $d a$ infraestrutura ou organizacional, destaca-se que é uma produção oral, pertencente a um oral formal e que está sob o domínio de uma linguagem radiofônica, portanto, será importante preocupar-se com a voz e a articulação vocal, a entonação, as pausas. A entonação dada, as pausas e o timbre da voz durante a produção favorecem a compreensão do texto. É um texto do eixo do argumentar cujo plano global é organizado em sequência argumentativa constituída por um fato, uma tese defendida, argumentos e contra-argumentos, organizados pelo produtor de acordo com as representações construídas por ele 
sobre a situação de argumentação na qual está envolvido e geralmente a apresentação da tese aparece no final do texto com o uso da ironia ou questionamento ao ouvinte. $\mathrm{O}$ tipo de discurso predominante é o discurso interativo monologado. No trabalho a ser desenvolvido com os alunos, as características do oral formal e a intencionalidade da variação das entonações e os timbres precisam ficar marcadas, bem como um trabalho sobre a sequência argumentativa não linear e com os elementos constitutivos do tipo de discurso interativo, mais especificamente, os tempos e as pessoas verbais e os advérbios e locuções adverbiais temporais e espaciais.

3. No nível dos mecanismos de textualização, ou melhor, das marcas linguísticas que são as responsáveis pela organização geral do texto no nível organizacional, encontram-se os elementos de conexão, mais especificamente os organizadores textuais lógico-argumentativos, alguns da oralidade (bem, então, agora), temporais (neste momento, agora). Nota-se que o advérbio agora pode aparecer como organizador lógico-argumentantivo e temporal, dependerá do uso no texto. Alem dos elementos de conexão, tem-se os elementos de coesão constituído predominantemente por anáforas nominais por substituição e repetição. A anáfora nominal aparece como recurso argumentativo característico da linguagem radiofônica. No processo de ensino desse gênero, os alunos precisarão construir uma grade de conhecimentos sobre os mecanismos de conexão e coesão nominal a fim de produzirem um comentário jornalístico radiofônico.

4. No nível dos mecanismos enunciativos, o uso do mecanismo de inserção de vozes é importante para a construção de uma argumentação, neste caso é necessário o ensino das diferentes formas de inserir a voz do outro nos comentários, ou em forma de discursos indiretos ou de citação. Em relação a modalização, o trabalho sobre a modalização lógica ou epistêmica e seu uso é fundamental no processo de convencimento em qual se encontra o produtor do comentário a fim de atingir o destinatário.

O modelo didático elaborado incide sobre diferentes elementos que permitem a compreensão e identificação de um gênero textual, ao mesmo tempo que possibilita um trabalho didático sobre as diferentes dimensões do gênero que, consequentemente, pode contribuir para o desenvolvimento de diferentes capacidades de linguagem.

\section{Considerações Finais}

Neste artigo, buscamos mostrar um processo de elaboração de um modelo didático de gênero textual, com o objetivo de servir de exemplo para a realização de outros processos de elaboração de modelos didáticos para o ensino de diferentes gêneros, visando ao desenvolvimento de capacidades de linguagem de aprendizes de diferentes faixas etárias e de diferentes gêneros. Ressaltamos, entretanto, que o procedimento realizado na elaboração do modelo didático, neste artigo apresentado, é apenas um exemplo de outros que possam existir, da mesma forma como acreditamos que o modelo didático decorrente dessa forma de elaboração possa ser apenas um dos possíveis modelos didáticos a serem feitos. Entretanto, também reconhecemos que o modelo didático elaborado possa ser adaptado para diferentes situações em que os aprendizes sejam de outros níveis de escolaridade.

A relação presente entre oralidade e escrita na forma de produção da atividade radiofônica e a necessidade de leituras de textos em fontes impressas (livros, jornais, por exemplo), bem como de acompanhamento de informações de outros meios como o televisivo e a internet, na produção do comentário, conforme constatado pelo desenvolvimento das etapas 2 e 3 do processo, possibilita o desenvolvimento de capacidades múltiplas, indo da oralidade para a escrita e da escrita para a oralidade.

Ainda em relação ao mesmo processo, apresentamos que algumas escolhas iniciais, como, por exemplo, o primeiro meio/suporte escolhido para a coleta dos exemplares dos comentários a serem a analisados não correspondia exatamente à nossa proposta, pois após uma analise inicial percebemos que eles apresentavam as características com as quais pensávamos em trabalhar, o que possibilitou, a nosso ver, a confirmação de que um mesmo gênero ao transitar por meios diferentes (atividade jornalística televisiva, atividade jornalística radiofônica) ele aportará algumas características diferenciadas.

A análise realizada e a escolha dos elementos que constituíram o modelo didático visaram, sobretudo, à elaboração de um modelo que considerasse o desenvolvimento das capacidades de linguagem, tendo conta, também uma compreensão da atividade linguageira e de outros elementos das condições de produção. Cada nível do modelo Didático se relaciona à uma capacidade de 
linguagem. O primeiro nível relaciona-se a capacidade de ação, o segundo nível liga-se às capacidades discursivas e terceiro e quarto nível às capacidades linguístico-discursivas.

\section{Notas}

1 Como atividades de linguagem compreende-se, por similitude, às esferas ou campos discursivos.

2 Para aprofundamento ver Bronckart, $1999 ; 2008$.

3 Inicialmente proposta no final do século XX, mais precisamente, década de 80 .

$4 \mathrm{O}$ termo 'transposição didática' foi introduzido pela primeira vez pelo sociólogo Michel Verret em 1975 e rediscutido por Yves Chevallard em 1985 em seu livro La Transposition Didatique, onde ele mostra as transposições ou os movimentos que um saber sofre quando passa de um campo científico (aquele que os cientistas descobrem) para o saber a ensinar, na escola (aquele que está nos livros didáticos) e, desse, para o saber verdadeiramente ensinado (aquele que realmente acontece em sala de aula) (SILVA, 2009, p.78).

5 Trecho da transcrição da entrevista realizada com o radialista $\boldsymbol{A}$ em 14 de janeiro de 2010.

6 Trecho da transcrição da entrevista realizada com o radialista $\boldsymbol{B}$ em 15 de janeiro de 2010.

7 Texto transcrito e nomeado como texto II. (Silva, 2009).

8 Texto transcrito e nomeado como texto IV. (Silva, 2009).

9 Texto transcrito e nomeado como texto IX. (Silva, 2009).

10 Texto transcrito e nomeado como texto VIII. (Silva, 2009).

11 Denominação utilizada na área do radiojornalismo para indicar o principal apresentador de um programa de notícias, esportes e etc. e que geralmente atua como coordenador da equipe de apresentação do programa.

12 A primeira versão deste quadro foi exposto em nossa dissertação de mestrado (Silva, 2009).

13 As palavras e expressões sublinhadas são indicadores do tipo de discurso interativo tal como proposto pelo interacionismo sociodiscursivo em Bronckart, 1999/2007.

14 Idem.
ADAM, Jean-Michel. Unités Redáctionalles et Genres Discursifs: Cadre Genéral pour une Appoche de lá presse écrite. Genres de La Presse Écrite. Pratiques, n.94, p.3-16. 1997.

. A Linguística Textual: Introdução à análise textual dos discursos. São Paulo: Cortez, 2008.

BAKTHIN, Mikhail. Estética da Criação Verbal. 4. ed. São Paulo: Martins Fontes, 2003.

BARBEIRO, Heródoto; LIMA, Paulo Rodolfo. Manual de radiojornalismo: produção, ética $\mathrm{e}$ Internet. 4. ed. Rio de Janeiro: Elsevier, 2003.

BARBOSA FILHO, André. Gêneros Radiofônicos. São Paulo: Paulinas, 2003.

BELTRÃO, Luiz. Jornalismo opinativo. Porto Alegre: Sulina, 1980.

COUTINHO, Maria Antónia. Texto(s) $e$ competência textual. Lisboa: FCG/FCT, 2003.

BRONCKART Jean Paul. 1999/2007. Atividade de Linguagem, Textos e discursos: Por um Interacionismo Sociodiscursivo. Tradução: Anna Raquel Machado, Péricles Cunha. 2. ed. São Paulo: EDUC.

.2006. Atividade de Linguagem, Discurso e Desenvolvimento Humano. Trad. e org: Anna Rachel Machado e Maria de Lourdes Meirelles Matêncio [et.al]. Campinas, SP: Mercado de Letras.

DOLZ, Joaquim; SCHNEUWLY, Bernard; HALLER, Sylvie. 2004. O oral como texto: como construir um objeto de ensino. IN: Gêneros orais e escritos na escola/tradução e organização Roxane Rojo e Glaís Sales Cordeiro. Campinas: Mercado de Letras.

DE PIETRO, Jean-François; DOLZ, Joaquim; DUFOR, Janine; ÉRARD, Serge; HALLER, Sylvie; KANEMAN, Massia; MORO, Christiane e ZAHND, Gabriela.1996/1997. Un modèle didactique $d u$ "debat": de l'objet social à la pratique scolaire. IN : Vers une didactique de l'oral ? ENJEUX - revue de didactique du français N. 39/40, Decembre 1996/Mars 1997.Genéve: CEDOCEF.

GUIMARÃES, Ana Maria de Mattos ; CAMPANI-

\section{Referências}

Horizontes, v. 32, n. 2, p. 21-34, jan./jun.2014 
CASTILHOS, Daiana ; DREY, Rafaela Fetzner. 2008. Gêneros de texto no dia-a-dia do Ensino Fundamental. 1. ed. Campinas: Mercado de Letras, v. $1.48 \mathrm{p}$.

MACHADO, Anna Rachel. 2010. Ensino de Gêneros textuais para o desenvolvimento do professor e de seu trabalho. IN: Letramento, discurso e trabalho docente: uma homenagem a Ângela Kleiman. Silvana Serrani (Org). Vinhedo: Editora Horizonte.

2009. O ensino e a aprendizagem de gêneros textuais. Lilia Santos Abreu-Tardelli e Vera Lúcia Lopes Cristovão (ORGs). Campinas: Mercado das Letras

2007. A perspectiva interacionista sociodiscursiva de Bronckart. IN: Gêneros, Teorias, Métodos, Debates. MEURER, BONINI, MOTTAROTH (orgs), São Paulo : Parábola, 2. ed. p. 237259

; Bronckart, Jean Paul. 2009. (Re-) configurações do trabalho do professor construídas nos e pelos textos: a perspectiva metodológica do grupo ALTER-LAEL. IN: $O$ trabalho do professor em uma nova perspectiva. Lília Santos AbreuTardelli e Vera Lúcia Lopes Cristovão (ORGs). Campinas: Mercado das Letras.

MACHADO, Anna Rachel; Cristóvão, Vera. 2009. A construção de modelos didáticos de gêneros: aportes e questionamentos para o ensino de gêneros. IN: O ensino e a aprendizagem de gêneros textuais. Lilia Santos Abreu-Tardelli e Vera Lúcia Lopes Cristovão (ORGs). Campinas: Mercado das Letras.

MACHADO, Anna Rachel; Abreu-Tardelli, Lilia Santos; LOUSADA, Eliane G. 2010. Resenha. 7. ed. São Paulo: Parábola.

MACHADO, Anna Rachel; Abreu-Tardelli, Lilia Santos; Lousada, Eliane G. 2011. Resumo. 8. Ed. São Paulo, Parábola.

MARCUSCHI, Luiz Antônio. Produção textual, análise de gêneros e compreensão. São Paulo: Parábola, 2008

MELO, José Marques. A opinião no jornalismo brasileiro. Petrópolis: vozes, 1985.

PRETTI, Dino. 2003. Análise de Textos Orais. 6. ed. São Paulo: Humanitas FFLCH/USP.

RABARDEL, P. 1993. Lês activités avec instruments. Documento-síntese apresentado para habilitação à direção de pesquisas. Paris, Univeristé Paris 8

SCHNEUWLY, Bernard. 2004. Gêneros e tipos de discurso: considerações psicológicas e ontogenéticas. IN: Gêneros orais e escritos na escola/tradução e organização Roxane Rojo e Glaís Sales Cordeiro. Campinas: Mercado de Letras.

SCHNEUWLY, Bernard; DOLZ, Joaquim. 2004. Os gêneros escolares - das prátcas de linguagem aos objetos de ensino. IN: Gêneros orais e escritos na escola/tradução e organização Roxane Rojo e Glaís Sales Cordeiro. Campinas: Mercado de Letras.

SILVA, Carla Messias Ribeiro da. 2009. O modelo didático do gênero comentário jornalístico radiofônico: uma necessária etapa para a intervenção didática. Dissertação de Mestrado. Pontifícia Universidade Católica de São Paulo. Paulo. pp. 187.

\section{Sobre a autora:}

Carla Messias: professora de Língua Portuguesa da rede pública do estado de Mato Grosso. Mestrado em Linguística Aplicada e Estudos da Linguagem (LAEL) pela Pontífícia Universidade Católica de São Paulo e Universidade Nova de Lisboa. Doutorado em LAEL pela PUC-SP e Universidade de Genebra. Membro do grupo de pesquisa Análise da Linguagem, Trabalho Educacional e suas Relações - (ALTER).

Artigo recebido em novembro de 2013

Artigo aprovado em março de 2014 